\title{
Gene expression profiling reveals the effects of light on adventitious root formation in lotus seedlings (Nelumbo nucifera Gaertn.)
}

Cheng Libao ${ }^{* *}$ (D, Han Yuyan ${ }^{1}$, Zhao Minrong ${ }^{1}$, Xu Xiaoyong ${ }^{1}$, Shen Zhiguang ${ }^{2}$, Wang Chunfei ${ }^{3}$, Li Shuyan ${ }^{4^{*}}$ and Hu Zhubing ${ }^{3}$

\begin{abstract}
Background: Lotus is an aquatic horticultural crop that is widely cultivated in most regions of China and is used as an important off-season vegetable. The principal root of lotus is degenerated, and adventitious roots (ARs) are irreplaceable for plant growth. We found that no ARs formed under darkness and that exposure to high-intensity light significantly promoted the development of root primordia. Four differential expression libraries based on three light intensities were constructed to monitor metabolic changes, especially in indole-3-acetic acid (IAA) and sugar metabolism.

Results: AR formation was significantly affected by light, and high light intensity accelerated AR development. Metabolic changes during AR formation under different light intensities were evaluated using gene expression profiling by high-throughput tag-sequencing. More than $2.2 \times 10^{4}$ genes were obtained in each library; the expression level of most genes was between 0.01 and 100 (FPKF value). Libraries constructed from plants grown under darkness (D/CK), under $5000 \mathrm{~lx}$ (E/CK), and under 20,000 lx (F/CK) contained 1739, 1683, and 1462 upregulated genes and 1533, 995, and 834 downregulated genes, respectively, when compared to those in the initial state (CK). Additionally, we found that 1454 and 478 genes had altered expression in a comparison of libraries D/CK and F/CK. Gene transcription between libraries D/F ranged from a 5-fold decrease to a 5-fold increase. Twenty differentially expressed genes (DEGs) were involved in the signal transduction pathway, 28 DEGs were related to the IAA response, and 35 DEGs were involved in sugar metabolism. We observed that the IAA content was enhanced after seed germination, even in darkness; this was responsible for AR formation. We also observed that sucrose could eliminate the negative effect of $150 \mu \mathrm{Mol}$ IAA during AR development.

\footnotetext{
*Correspondence: Ibcheng@yzu.edu.cn; Isydbnd@163.com

'School of Horticulture and Plant Protection, Yangzhou University, Yangzhou, Jiangsu, P. R. China

${ }^{4}$ College of Guangling, Yangzhou University, Yangzhou, Jiangsu, P. R. China

Full list of author information is available at the end of the article
}

C C The Author(s). 2020 Open Access This article is licensed under a Creative Commons Attribution 4.0 International License, which permits use, sharing, adaptation, distribution and reproduction in any medium or format, as long as you give appropriate credit to the original author(s) and the source, provide a link to the Creative Commons licence, and indicate if changes were made. The images or other third party material in this article are included in the article's Creative Commons licence, unless indicated otherwise in a credit line to the material. If material is not included in the article's Creative Commons licence and your intended use is not permitted by statutory regulation or exceeds the permitted use, you will need to obtain permission directly from the copyright holder. To view a copy of this licence, visit http://creativecommons.org/licenses/by/4.0/ The Creative Commons Public Domain Dedication waiver (http://creativecommons.org/publicdomain/zero/1.0/) applies to the data made available in this article, unless otherwise stated in a credit line to the data. 
(Continued from previous page)

Conclusions: AR formation was regulated by IAA, even in the dark, where induction and developmental processes could also be completed. In addition, 36 genes displayed altered expression in carbohydrate metabolism and ucrose metabolism was involved in AR development (expressed stage) according to gene expression and content change characteristics.

Keywords: Lotus, ARs, Light, Gene, IAA, Sucrose

\section{Background}

Lotus is widely cultivated in the southern region of the Yellow River Basin; a lotus cultivation area of approximately 200,000 ha is mainly distributed in Hubei, Jiangsu, Anhui, Guangdong, and Shandong provinces. The lotus is commonly used for three main purposes: lotus flowers can be used for ornamental displays, lotus rhizomes can be used as vegetables, and lotus seed can be used as a food source. Lotus rhizome can be continuously supplied to the local market as a vegetable owing to its simple storage in soil from October to April of the next year. Traditional cuisine such as steamed lotus, boiled lotus, and lotus soup are very popular among consumers. Several processed parts of lotus plants, including lotus starch, lotus drink, and salted lotus, are exported to a number of countries in Asia, America, and Europe [1]. In addition, a large number of secondary metabolites make the lotus a constituent of traditional Chinese medicine. Recently, with greater industrialization, lotus cultivation has increased to cover the largest area among all the aquatic vegetables. Therefore, studies related to the theory and practice of lotus use have been attracting increasing attention [2, 3].

Light, including photoperiod, light quality, and light intensity, is a basic condition that is involved in several aspects of plant development and growth, such as root formation, photosynthesis, flowering, fruit development, and plant morphogenesis [4-6]. Many metabolic processes that depend on light signals during plant growth are induced by hormonal signaling [7, 8], suggesting that hormone action occurs downstream of the light signal transduction pathway [9-11]. Light is known to regulate the entire process of root formation [12-14]. A number of factors involved in the light signaling pathway, such as reactive oxygen species, abscisic acid, and sugar, have been to found to affect root development [15-17]. Indole-3acetic acid (IAA) is synthesized in vigorous organs under light regulation $[18,19]$. Depending on the exposure to light, IAA plays a critical role in the developmental process of adventitious roots (ARs), including induction, development, and expression of roots [20, 21]. Improvement of endogenous IAA content by exogenous application of IAA significantly promotes cell division of root primordium, which directly leads to a positive effect on AR development [22]. Further, studies show that changing auxin metabolism or auxin sensitivity in plants is helpful for the formation of ARs [23, 24]. It has been reported that cytokinin, which regulates cell division, is also involved in AR formation due to its effect on auxin metabolism [20]. Therefore, IAA is considered a direct regulator of the complex network in regulating AR formation.

Analysis of gene expression or regulation in the whole genome is the most effective approach to understand AR formation. Studies over recent decades involved in auxin metabolism or responses related to ARs have shown that many genes participate in IAA synthesis, transport, or response which help accelerate developmental processes of ARs [25]. Until now, two kinds of IAA transport (influx carriers and efflux carriers) have been reported. The AUX1/LAX family, which are influx carriers, has a major influence on root development by triggering IAA distribution in plants [26]. The AUX1/ LAX gene family contains several members, and different expression profiles are found in various tissues [27]. Ahkami et al. (2013) [28] reported that auxin also affects the IAA content in plants by regulating GH3 expression in Petunia hybrida. The above data indicate that various functions exist for members of the AUX1/LAX family, although these genes are involved in AR development. PIN, as an efflux carrier, is expressed in the root primordia and is required for root formation [29, 30]. An auxin-induced gene, ARL1, is found to participate in cell division relevant to AR formation [25]. In addition, several auxin responsive factors, such as ARF6, ARF8, and ARF17, are also involved in AR development [31]. Therefore, the biological process of ARs formation is regulated by multiple genes.

Lotus needs considerable nutrition to support plant growth. However, the principal root cannot be developed in the plant owing to long periods of evolution; therefore, ARs become the major mediators for uptake of water and mineral substances for adequate swelling of rhizome, which is essential for production or breeding of lotus. Recently, we have found that ARs of seedling hypocotyl significantly affect plant growth. Early formation of ARs or more ARs number can promote swelling of rhizome. The ARs of lotus are primordially latent and need to be induced by IAA [32] for the developmental process to start. ARs have been found to frequently locate in two sites in lotus plants, namely the seedling 
hypocotyl and the internodes of storage organs [33]. In general, the number of ARs in the seedling hypocotyl is lower than that in the internodes of storage organs owing to the considerable amount of nutrition that is needed for plant growth. Primordial roots are differentiated from normal cells triggered by hormones or other environmental factors and developed at the pericycle $[34,35]$. The biological process of AR formation includes three periods: induced stages, initial developmental stages, and emergence from the epidermis [36, 37]. In the induced stage, meristematic cells are developed from normal cells; the sink establishment phase is thus established. In the initial developmental stage, the primordium relevant to ARs is formed and developed [38], and finally, ARs protrude from the epidermis [39]. The above three biological processes are affected by light.

Recently, we found that exogenous application of ethylene, IAA, and mechanical damage significantly affected lotus AR formation derived from the change in endogenous IAA content under normal light conditions. In darkness, no emergence of ARs occurs, although the above substances were applied, suggesting that light is a necessary factor for lotus AR development. However, there was no direct evidence for the light-dependent IAA regulation on AR formation. Therefore, in this study we constructed four gene libraries to monitor gene expression from the induced stage to the expression stage of AR development. At the same time, changes in IAA content were also documented.

\section{Results}

\section{Light promotes AR development}

To investigate the effect of light quality on lotus AR formation, lotus was exposed to various light intensities, including darkness, and 5000 and 20,000 lx. No ARs were formed in the lotus under darkness (Table 1), whereas lotus could develop ARs when exposed to light. Thus, AR formation appears to be dependent on light intensity. After germination, ARs could be observed on the second day under 20,000 lx and on the fourth day under $5000 \mathrm{~lx}$, indicating that light regulates AR development (Fig. 1a). Next, we observed the microstructure of the hypocotyl where the ARs emerged. When exposed to light, AR development could be clearly divided into three stages: induced process, developmental process, and expressed process (Fig. 1b). Under darkness, the AR primordium was present, but failed to break out of the epidermis (Fig. 1b).

\section{Light affects IAA content}

IAA has been characterized as an inducer of ARs. To investigate whether the regulation of light on ARs is dependent on IAA, we monitored the IAA contents of lotus seedlings under various light intensities (darkness, 5000,1500 , and $30,000 \mathrm{~lx}$ ). IAA content gradually increased with exposure time to light and reached a maximum within 4 days and subsequently decreased; interestingly, a significant increase in IAA content was also observed in darkness. Among the different light intensities, the increased level of IAA in lotus was the highest under 30,000 lx. The above results showed that another factor, which was regulated by light, existed in coordinating the development of ARs with IAA, (Fig. 2).

\section{Effects of light on transcriptome profiling}

To dissect the underlying mechanism by which light regulates AR development, we comparatively analyzed the transcriptome profile of lotus before and after exposure to various light intensities (darkness, and 5000 and 20, $000 \mathrm{~lx}$ ) by constructing four different libraries: CK0 (before treatment), D (3-d exposure under darkness), E (3-d exposure under $5000 \mathrm{~lx}$ ), and $\mathrm{F}$ (3-d exposure under 20, $000 \mathrm{~lx}$ ). Analysis of quality control showed that the reads derived from RNA-seq libraries covered the whole lotus genome, as evidenced by the flat curve of the obtained reads (Additional file 1: Fig. S1). Approximately $1.2 \times$ $10^{9}$ reads were obtained, of which more than $97 \%$ were clean reads. Approximately $83 \%$ reads were successfully mapped into the lotus genome and $73 \%$ of the reads were unique (Additional file 1: Table S1). PCA showed a high correlation among the three biological replicates (Fig. 3a). In total, 25,766 genes were obtained, and over $86 \%$ of genes were present in each library (Fig. $3 \mathrm{~b}$ ). The FPKM values ranged from 0.01 to 100 (Fig. 3c,d). Analysis of differentially expressed genes (DEGs) showed that when compared with the expression before treatment (in library CK0), 1739, 1683, and 1462 genes were upregulated and 1533, 995, and 834 genes were downregulated when lotus plants were exposed to 3 days under darkness (in library D), or under $5000 \mathrm{~lx}$ (library E) or 20,000 lx (library F), respectively, (Fig. 4a,b, Additional file 1: file S). Further DEGs analysis between

Table. 1 Effect of various light intensities on the number and rates of AR

\begin{tabular}{|c|c|c|c|c|c|c|c|c|c|c|c|c|}
\hline \multirow[t]{2}{*}{ Treatments } & \multicolumn{2}{|l|}{$1 \mathrm{~d}$} & \multicolumn{2}{|l|}{$2 \mathrm{~d}$} & \multicolumn{2}{|l|}{$3 d$} & \multicolumn{2}{|l|}{$4 \mathrm{~d}$} & \multicolumn{2}{|l|}{$5 \mathrm{~d}$} & \multicolumn{2}{|l|}{$6 \mathrm{~d}$} \\
\hline & AN & $\mathrm{AR}(\%)$ & AN & $A R(\%)$ & AN & $\mathrm{AR}(\%)$ & AN & AR (\%) & AN & AR (\%) & AN & AR (\%) \\
\hline Darkness & Oc & $0 c$ & $0 c$ & $0 c$ & $0 b$ & $0 c$ & od & od & $0 c$ & Oc & $0 c$ & $0 c$ \\
\hline $5000 \mathrm{~lx}$ & $0.53 b$ & $18 b$ & $0.61 \mathrm{c}$ & $43 b$ & $2.86 c$ & $67 b$ & $4.33 c$ & $77 b$ & $5.63 b$ & $88 a$ & $7.84 b$ & $94 a$ \\
\hline $30,000 \mathrm{~lx}$ & $1.53 a$ & $51 a$ & $4.32 a$ & $85 a$ & $4.57 a$ & $94 a$ & $8.83 a$ & $97 a$ & $10.72 a$ & $98 a$ & $12.34 a$ & $100 a$ \\
\hline
\end{tabular}




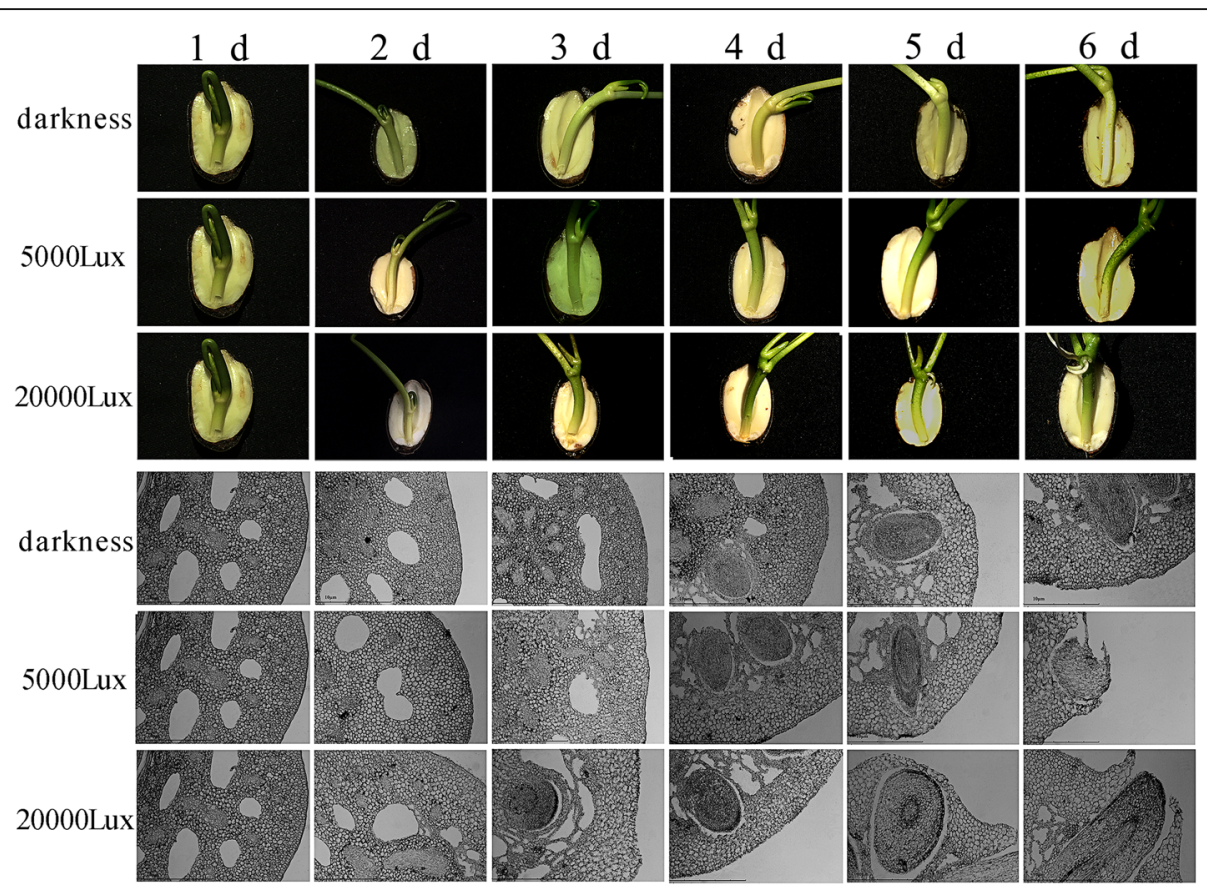

Fig. 1 Changes in morphology and microstructure of ARs after treatment with various light intensities. a Changes in the morphology of ARs in lotus under darkness, and under 5000 and 20,000 Ix light intensities over 5 days. b Changes in the microstructure of ARs in lotus under darkness, and under 5000 and 20,000 Ix light intensities over 5 days

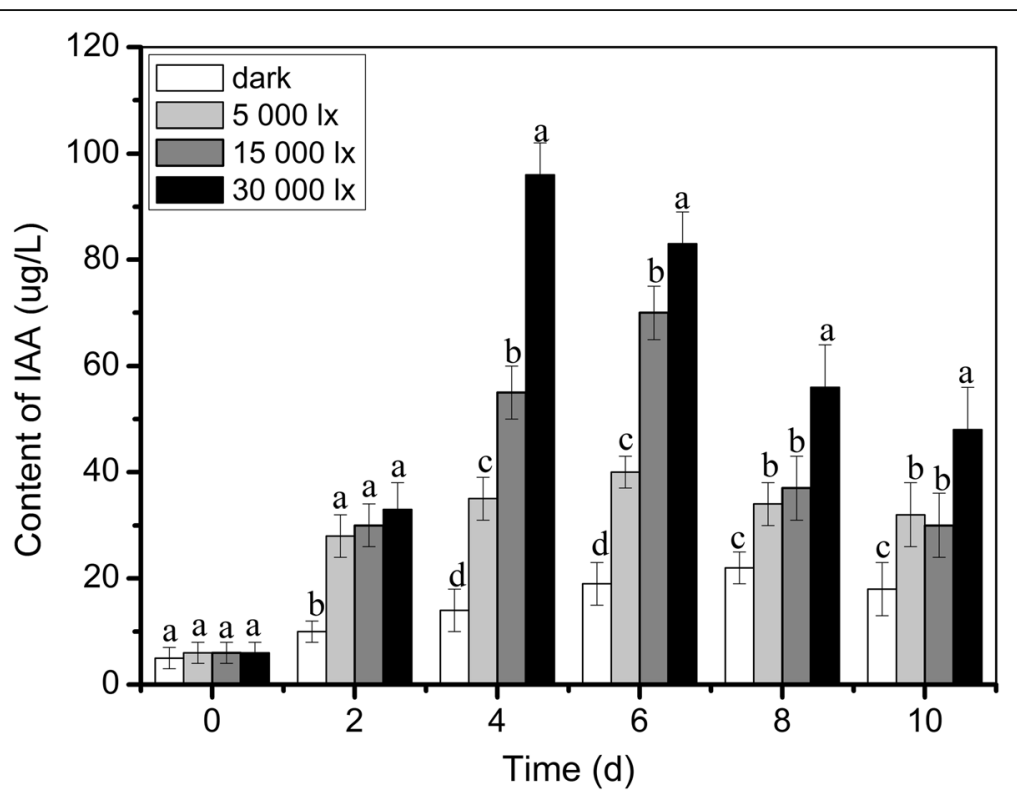

Fig. 2 IAA and sucrose content during AR development. a IAA content at 0, 2, 4, 6, 8, and $10 \mathrm{~d}$ after treatment under darkness, and under 5000, 15,000 , and 30,000 Ix light intensities in lotus seedlings. b Sucrose content at $0,2,4,6,8$, and $10 \mathrm{~d}$ after treatment under darkness, and under $5000,15,000$, and 30,000 Ix light intensities in lotus 

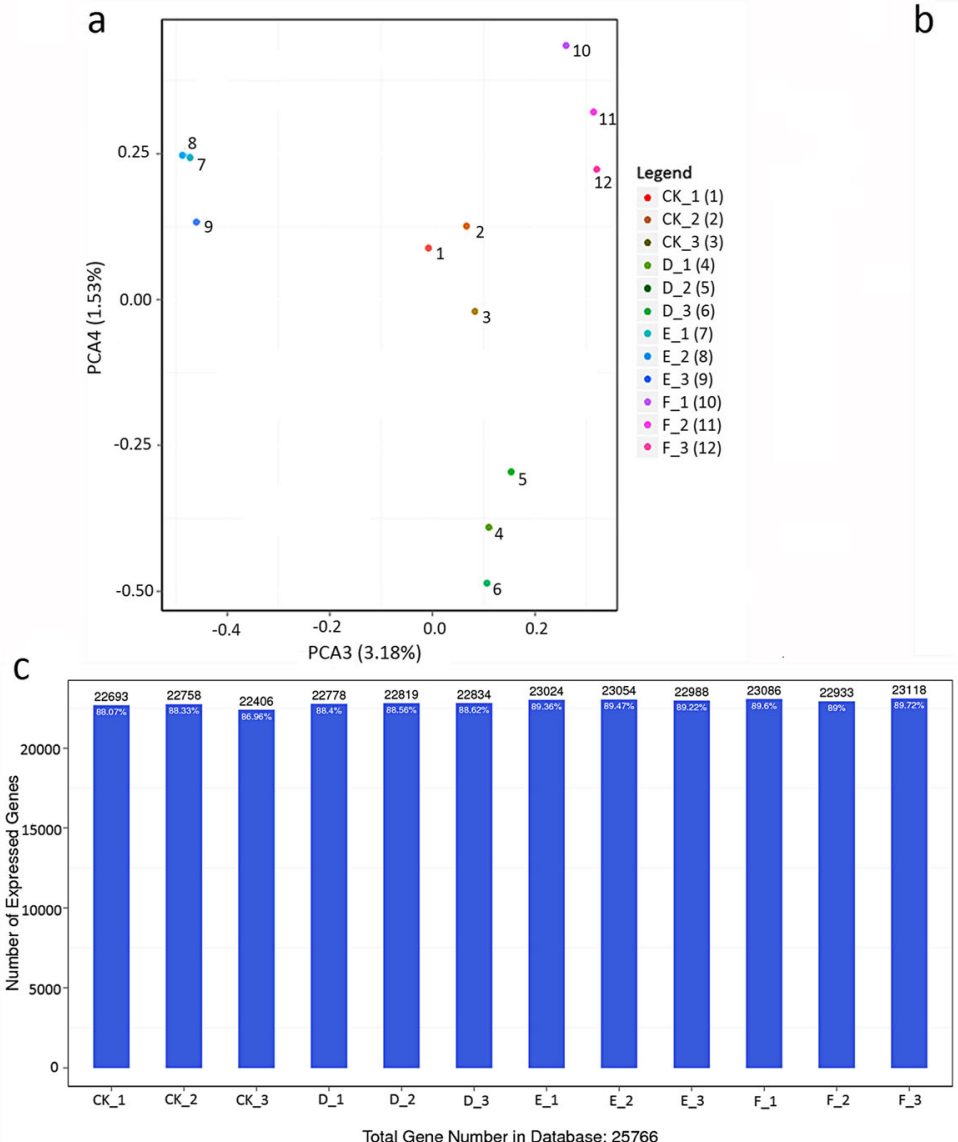

b

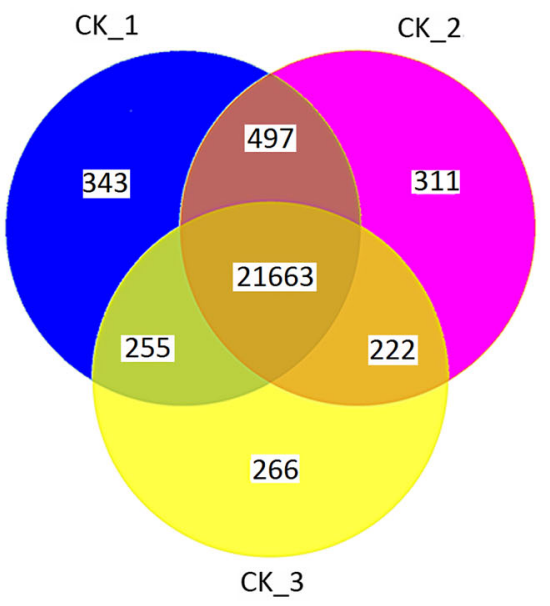

d

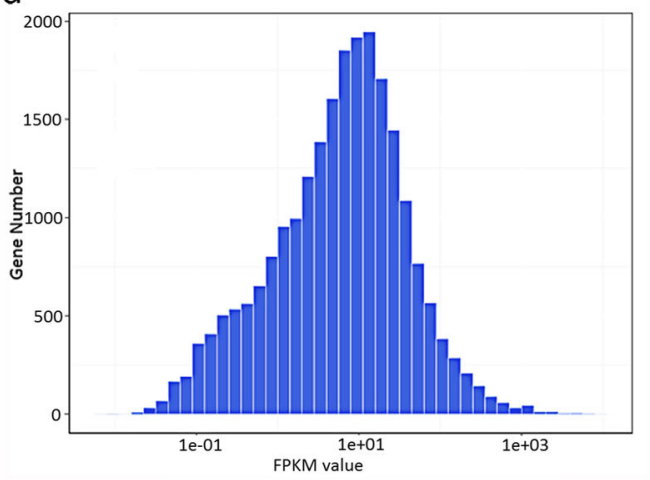

Fig. 3 Essential data derived from the RNA-seq technique. a The result of principal component analysis between the components in libraries. $\mathbf{b}$ Venn Chart of co-expressed genes among the repeated samples. c Number of identified genes in all libraries. $\mathbf{d}$ Histogram distribution of genes on the expression level of each sample

libraries D and F, only 240 genes satisfied the threshold of a DEG (Fig. 4c,d).

\section{Light influences carbohydrate metabolism and hormone signal transduction}

In terms of the dramatic difference in AR development between the 3-d exposure of libraries D and F, we analyzed their DEGs using the KEGG tool. These DEGs could be classified into five groups, including cellular processing, environmental information processing, genetic information processing, metabolism, and organismal systems. Further analysis showed that 20 DEGs were involved in signal transduction in the group of environmental information processing and 36 DEGs were related to carbohydrate metabolism in the metabolism processing group (Fig. 5a), indicating that they might be the major regulatory pathways during light-dependent AR development. In support, the expression of genes involved in plant hormone signal transduction and the metabolism of starch and sucrose was also altered (Fig. 5b).
Furthermore, we employed reverse-transcriptase quantitative polymerase chain reaction (qRT-PCR) to confirm the results of RNA-seq. Ten genes, including pectinesterase, peroxisomal adenine nucleotide carrier 1-like, indole-3acetic acid-amido synthetase, ethylene-responsive transcription factor ERF118, peroxisomal(S)-2-hydroxy-acid oxidase GLO1-like, pyruvate decarboxylase 1, respiratory burst oxidase homolog protein B-like, sucrose synthase, lightregulated protein, photosynthetic NDH subunit of lumenal location 1, which are involved in various processes such as sugar metabolism, IAA signal transduction, energy metabolism, photosynthesis, ethylene signal transduction, and respiratory metabolism, were chosen to investigate their expression under three light intensities (darkness, $5000 \mathrm{~lx}$, and $30,000 \mathrm{~lx}$ ) by qRT-PCR. Generally, the expression of these genes was similar to that derived from the RNA-seq dataset (Fig. 6).

\section{Role of sucrose in lotus AR formation}

To analyze the role of sucrose in AR formation, a complementary experiment between IAA and sucrose was carried 

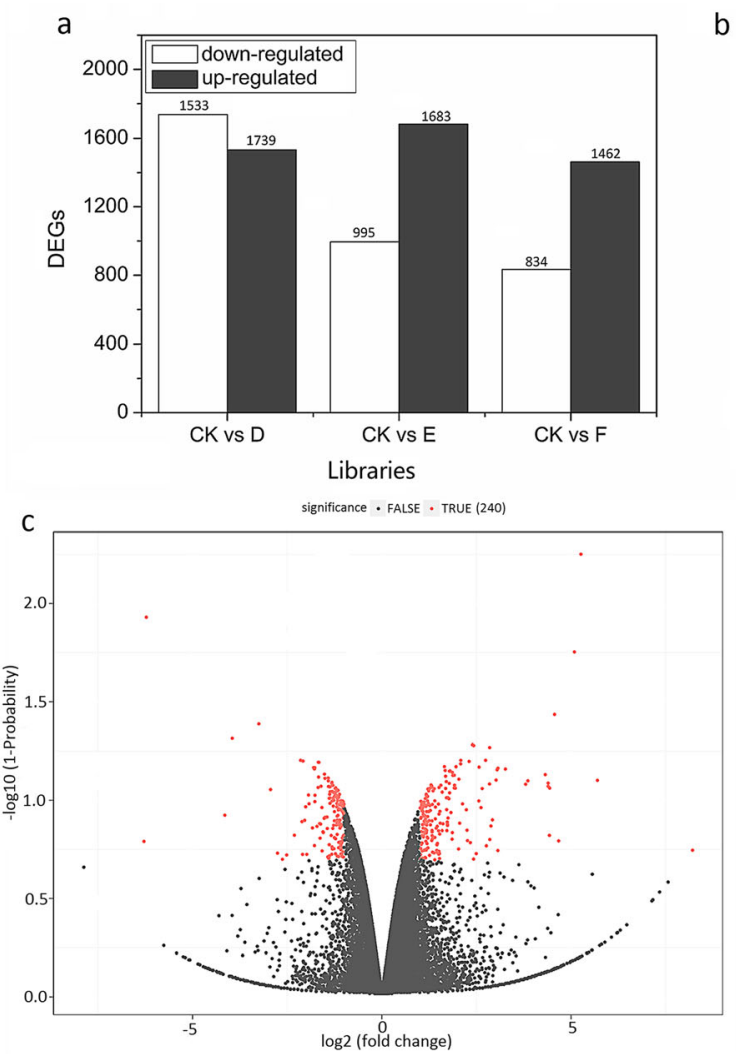

b

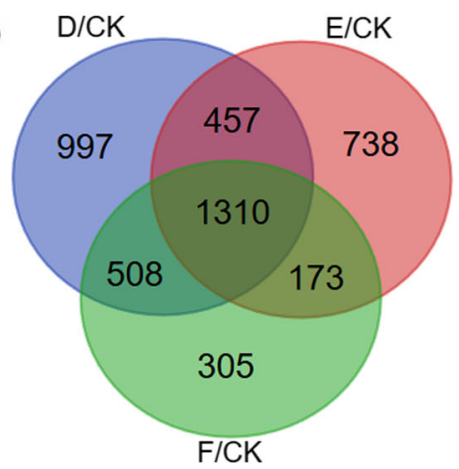

d

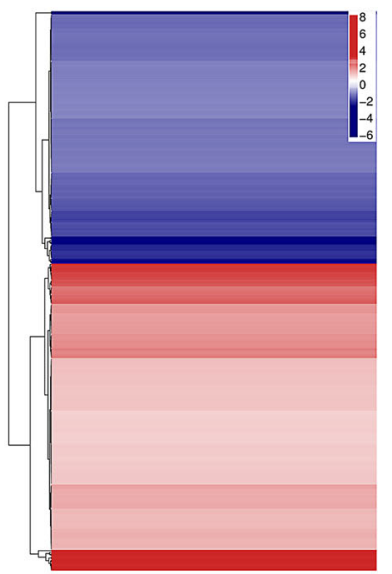

Fig. 4 Identification of differentially expressed genes under different light intensities. Number of DEGs in the D/CK, E/CK, and F/CK libraries. b Selected expressed genes in the D/CK, E/CK, and F/CK libraries. c Identification of DEGs in F/D libraries. $\mathbf{d}$ Distribution of expression of these DEGs identified in the F/D libraries

out under normal light conditions. We found that $60 \mathrm{mg} / \mathrm{L}$ sucrose and $150 \mu$ mol IAA significantly inhibited AR development, while $20 \mathrm{mg} / \mathrm{L}$ sucrose and $10 \mu \mathrm{mol}$ IAA dramatically promoted the formation of lotus ARs. The inhibition by $60 \mathrm{mg} / \mathrm{L}$ sucrose could be compensated by application of exogenous $10 \mu \mathrm{mol}$ IAA, although no obvious difference was found with control seedlings. Furthermore, exogenous application of $20 \mathrm{mg} / \mathrm{L}$ sucrose dramatically increased AR development in seedlings treated with $150 \mu \mathrm{mol}$ IAA (Fig. 7). According to the change in IAA under various light intensities, IAA was an absolute inducer of ARs in lotus. We observed that ARs could be developed at the induced and developed stage under $150 \mathrm{mg} / \mathrm{L}$ IAA treatment (although they could not break out of the epidermis) and remove the inhibitory effect of sucrose. Based on these observations, we believe that sucrose might be involved in the expressed state of lotus AR formation (Fig. 8).

\section{Discussion}

Light (light quality, photoperiod, and light intensity) is an essential environmental factor that affects most plant metabolic processes. There is evidence that light intensity and light quality affect AR development and the photosynthate quantity of Hypericum perforatum [40].
Chen et al. (2019) reported that root generation and overall plant development can be dramatically promoted under available light intensity conditions in Haworthia [41]. At the same time, light quality is shown to influence ARs in Coleus [42]. We found that different light intensities have various roles in the formation of ARs in lotus. The seedlings grown under darkness condition could not form ARs, although high light intensity promoted the developmental process of ARs (Fig. 1, Table 1). Interaction of light with other factors is cooperatively involved in root development [43]. Light regulation of AR development is often derived from the sucrose content of photosynthate, and this effect is mainly reflected in the root number $[44,45]$. Sorin et al. (2005) found that the role of IAA in regulating AR formation in Arabidopsis thaliana is dependent on light conditions. IAA synthesis and accumulation in plants can induce the formation of founder cells of ARs [21]. In our study, we found that IAA content increased with or without light treatment, and that plants under high light intensity had higher IAA content compared with that in plants under low light intensity or darkness (Fig. 2), suggesting that IAA synthesis was affected by light intensity in lotus. Therefore, we believed that ARs formation affected by light was directly regulated by IAA. 

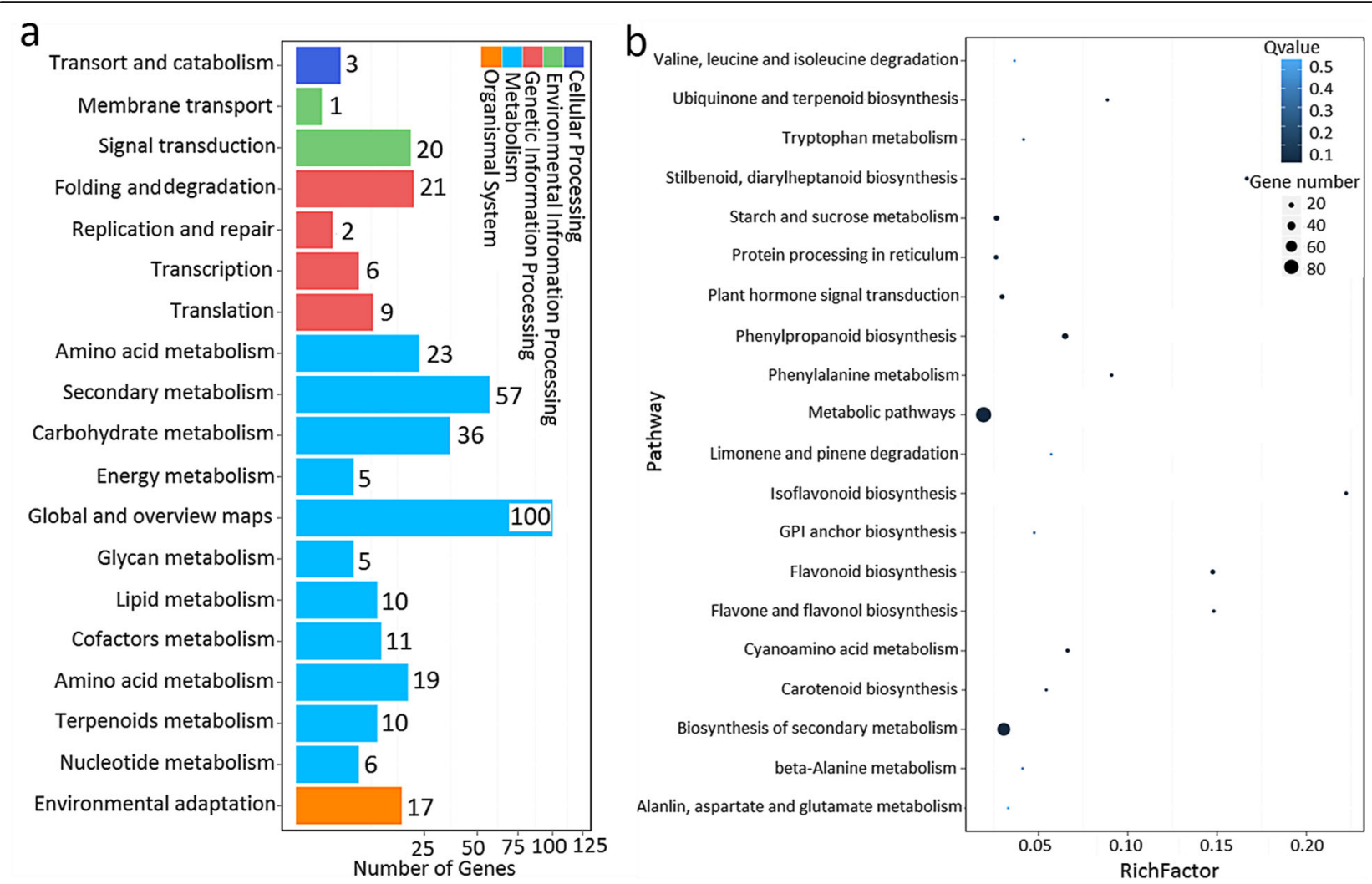

Fig. 5 Functional analysis of DEGs in the F/D libraries. a KEGG analysis of these DEGs in different metabolic processes. $\mathbf{b}$ Display of the top 20 enriched pathway terms in F/D libraries. The rich factor was the ratio of differentially expressed mRNAs. Numbers annotated in this pathway term apply to all gene numbers annotated in this pathway term; the greater the rich factor, the greater the degree of enrichment

Lotus is an important aquatic ornamental plant, and a vegetable in China. ARs are a necessary secondary organ for mainly water and nutrition uptake because no principal roots occur in the plants [32, 46]. Similar to previous reports, three obvious developmental periods, such as induced period of root primordium, developmental period, and expressed period (stages of breaking out epidermis) were found for lotus ARs [32]. We found that many factors including plant hormones [32, 47], mechanical damage [33], and sucrose [data not shown] are all involved in AR development. In addition, several important genes or regulators (miRNAs) have been shown to perform critical roles in AR formation [48]. To monitor the metabolism mechanism regulated by light, gene expression was identified under various light intensities. We found that a large number of genes enhanced expression and decreased expression in the three libraries (D/CKO, E/ $\mathrm{CK} 0$, and F/CKO), respectively. Based on these datasets, several key genes that demonstrated clear changes in expression were also implored in the F/D libraries (Additional file 1: file S1). Therefore, we concluded that the biological process of AR formation regulated by light was highly complex.

\section{Role of IAA or sucrose in AR development}

Auxin is believed to be a critical hormone that participates in various biological processes such as organogenesis, fruit development, flowering, and adaptation to stresses [39, 49-52]. Auxin metabolism, including auxin synthesis, transport, and homeostasis are known to be involved in the regulation of plant development, such as root formation, shoot development, and reproduction [53]. At the same time, auxin is believed to be a necessary regulator to switch the process from xylogenesis (this process is averse to AR formation) to root development [54]. In the past decades, many important genes relevant to IAA metabolism or the response involved in root formation have been identified $[55,56]$. In this study, four libraries were treated with different light intensities were constructed using Solexa technology (Fig. 3), which has proved to be an efficient way to analyze gene expression under certain conditions (March 2011). We found that a total of 4884 genes and 2040 genes demonstrated increased expression and decreased expression, respectively, in the three libraries $(\mathrm{D} / \mathrm{CK} 0, \mathrm{E} / \mathrm{CK} 0$, and F/CK0, respectively,) (Fig. 4). A total of 28 genes including auxin synthesis, responding (inducing), auxin transporter, and auxin 

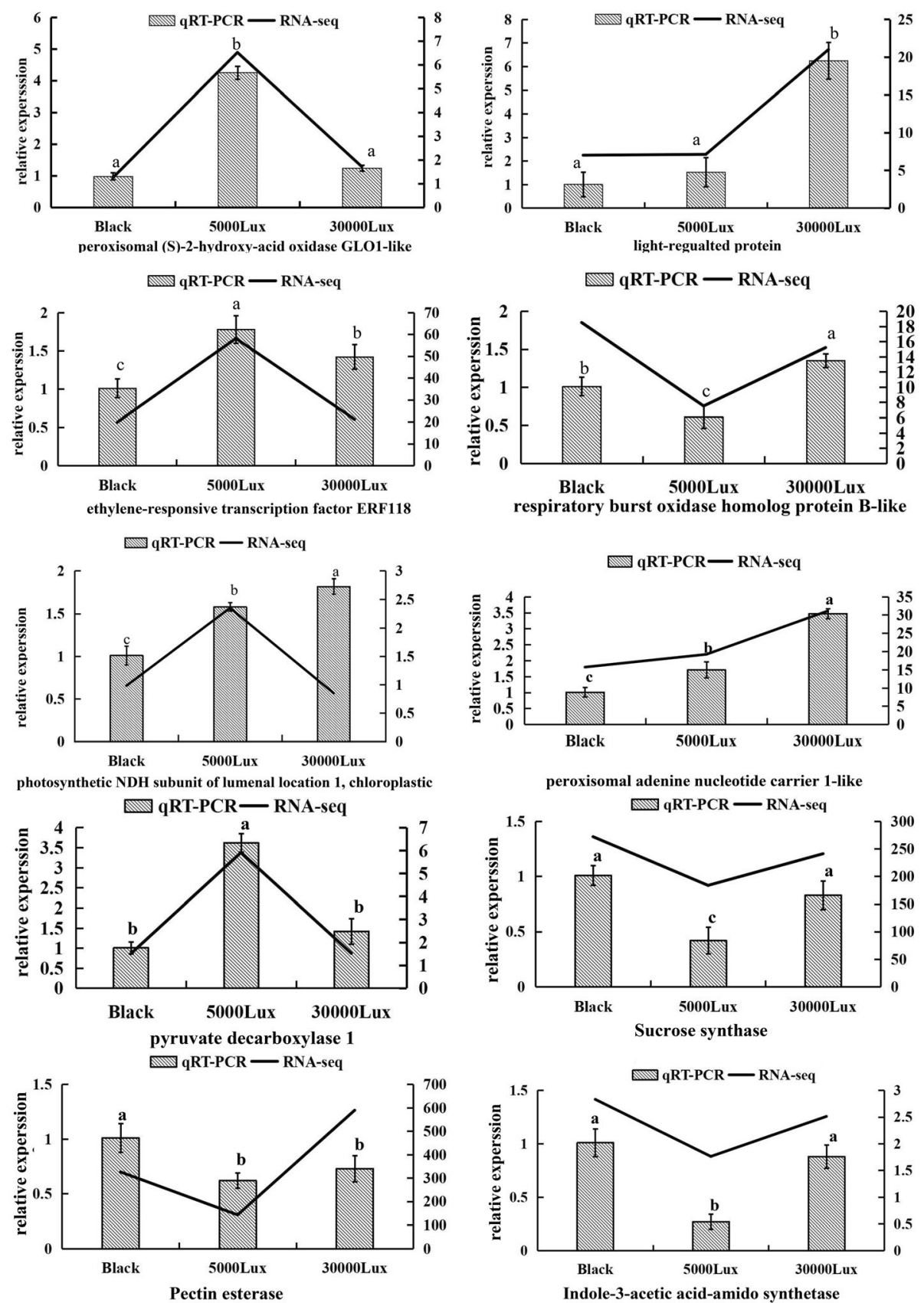

Fig. 6 Expression analysis of ten genes under darkness, and under 5000 and 20,000 lx light intensities by qRT-PCR. The genes selected in this study were pectinesterase, peroxisomal adenine nucleotide carrier, indole-3-acetic acid-amido synthetase, ERF118, peroxisomal (S)-2-hydroxy-acid oxidase GLO1, pyruvate decarboxylase 1, respiratory burst oxidase homolog protein B, sucrose synthase light-regulated protein, the photosynthetic NDH subunit

repressed protein was identified in the F/D libraries. However, it was shown that $G H 3$, which was responsive for IAA synthesis did not change expression (Table 2), suggesting that another method for IAA synthesis existed according to the change in IAA content. As IAA transporter, auxin is considered an important factor involved in AR development at the induction stages of root primordium development $[26,57,58]$. Interestingly, we observed that the expression of auxin transport-relevant genes such as auxin efflux carrier component $1 \mathrm{c}$ and auxin transporter-like protein 2 were not severely affected by light intensity, which indicated that the difference in ARs formation was not a result from IAA transport in the darkness and 20,000 lx light intensity (Table 2). 


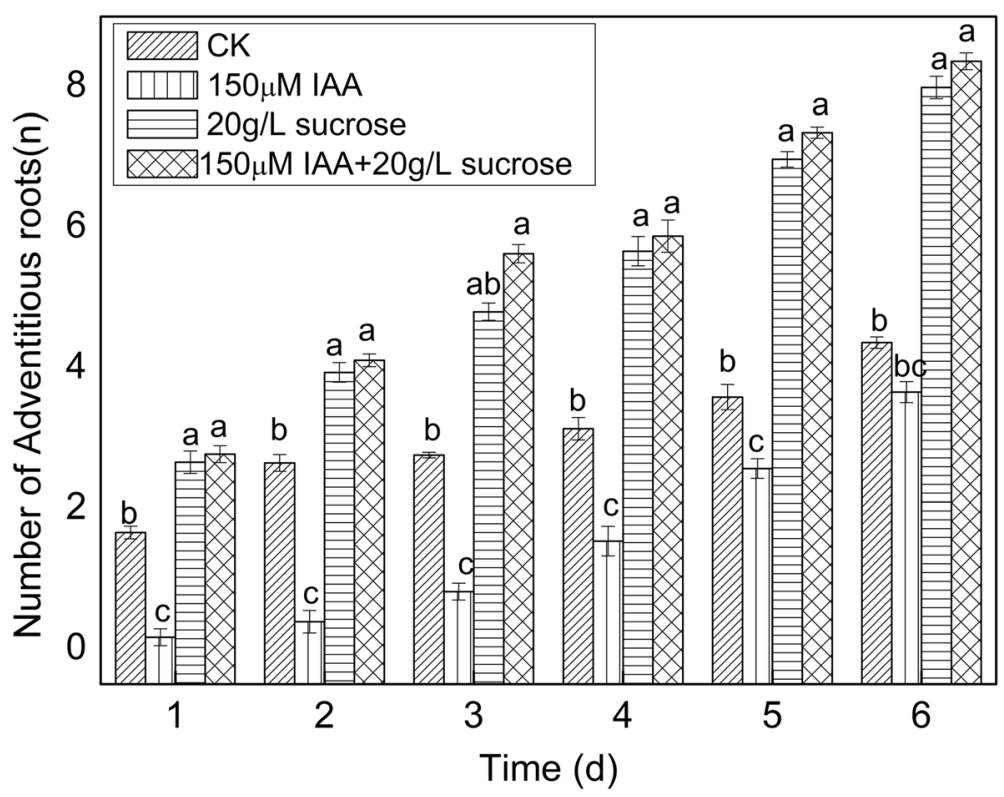

Fig. 7 Complementary experiment between IAA and sucrose. Seeds were treated with $150 \mu \mathrm{M}$ IAA, $20 \mathrm{~g} / \mathrm{L}$ sucrose, and $150 \mu \mathrm{M}$ IAA $+20 \mathrm{~g} / \mathrm{L}$ sucrose for two days with water treatment as the control, and then transferred into water for germination. The number of ARs for each treatment was counted at six time points (days 1, 2, 3, 4, 5, and 6 post-treatment)

Plant growth is dependent on cell division, differentiation, and elongation. Sugar (especially sucrose) signals are involved in the above biological processes by inducing many important genes [59-62]. In recent years, sucrose has been found to regulate root growth by increasing root length [63]. Le et al. (2019) reported that application of available concentrations of sucrose in culture medium can significantly promote AR growth [64]. At the same time, sucrose not only affects AR growth, but also influences the substance metabolism of ARs in

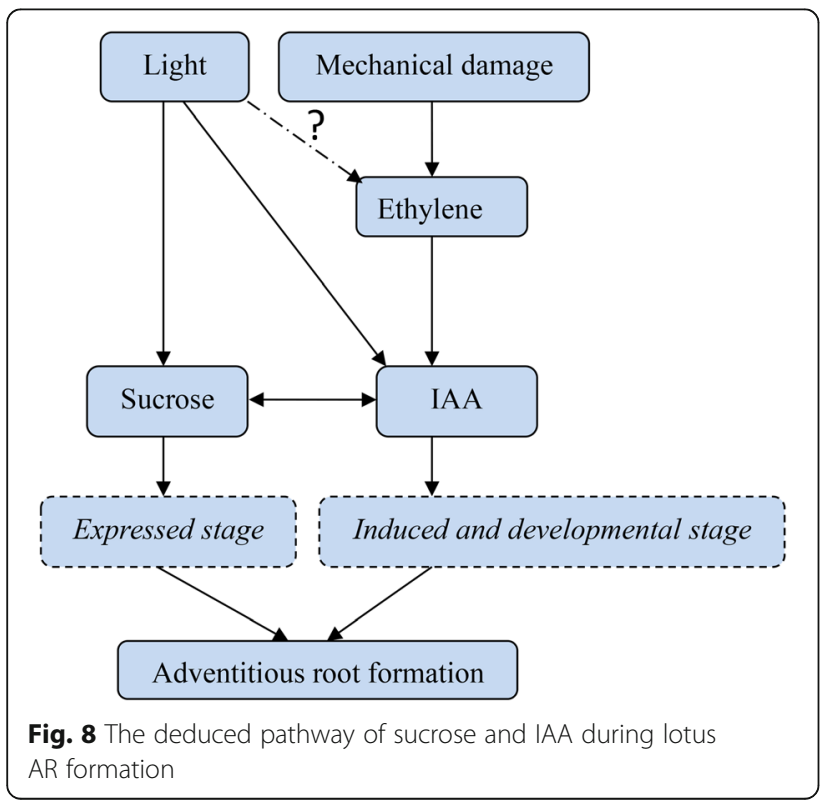

Echinacea pallida [65]. Takahashi et al. (2003) showed that the role of sucrose on AR formation is similar to that of hormones and that the induction stage of AR development is strictly controlled by sucrose [66]. In this study, we found that several important genes related to sucrose synthesis had enhanced expression in the F/D libraries, and the content of sucrose was higher than that in darkness. Sucrose synthase and sucrose-phosphatase were the critical enzymes in sucrose synthesis (Fig. 5, Table 3). It has been shown that the expression of these genes can lead to an increase in the sucrose content [67]. The change in sucrose content by modifying the activity of sucrose synthase and sucrose-phosphatase is beneficial for maintaining fruit storage quality $[68,69]$. We observed that the expression of genes encoding sucrose synthase and sucrose-phosphatase was enhanced by 3.91- and 1.29-fold in the F/D libraries (Table 3). A high correlation was found between gene expression and sucrose content, suggesting that sucrose metabolism was necessary for AR development in lotus. In addition, we observed that a complementary phenomenon existed between IAA and sucrose during AR formation, which could explain how IAA and sucrose cooperatively regulated lotus AR formation according to the change in IAA and sucrose content. A crosstalk exists is known to exist between ethylene and auxin in controlling root development. Exogenous application of auxin can increase ethylene content, and plants treated with ethephon also improve the content of endogenous IAA content $[22,24,70]$. Therefore, we believe that a new model of interaction between sucrose and IAA is involved in lotus root development. 
Table 2 Gene expression involved in IAA metabolism in the D/CK, F/CK, and F/D libraries

\begin{tabular}{|c|c|c|c|c|}
\hline ID & D/CKO libraries & F/CKO libraries & F/D libraries & Function annotation \\
\hline $104,589,706$ & 6.54 & - & -1.83 & Auxin induced protein $15 \mathrm{~A}$ \\
\hline $104,587,078$ & 4.51 & - & - & Auxin responsive protein SAUR64 \\
\hline $104,602,283$ & 3.98 & - & - & Auxin responsive protein SAUR36 \\
\hline $104,591,786$ & 3.94 & 3.82 & - & Auxin responsive protein SAUR71 \\
\hline $104,600,574$ & - & 3.60 & - & Auxin binding protein ABP19a \\
\hline $104,591,143$ & 1.57 & - & - & Auxin induced protein $\mathrm{X} 10 \mathrm{~A}$ \\
\hline $104,599,427$ & 1.51 & - & - & Auxin biosynthetic process \\
\hline $104,596,961$ & 1.46 & 1.52 & - & Auxin transporter like protein 2 \\
\hline $104,609,680$ & 1.39 & - & -1.07 & Auxin transporter like protein 3 \\
\hline $104,592,479$ & 1.25 & 1.24 & - & Auxin responsive protein IAA5 \\
\hline $104,592,764$ & -1.05 & - & - & Auxin response factor 2 \\
\hline $104,610,814$ & -1.09 & - & - & Auxin response factor 6 \\
\hline $104,604,767$ & -1.19 & -1.48 & - & Auxin response factor 18 \\
\hline $104,601,926$ & -1.23 & -1.09 & - & Auxin efflux carrier component $1 \mathrm{c}$ \\
\hline $104,612,448$ & -1.26 & -1.0 & - & Auxin responsive protein IAA4 \\
\hline $104,609,555$ & -1.27 & - & - & Auxin induced protein 22B \\
\hline $104,593,954$ & -1.33 & -1.04 & - & Auxin response factor 1 \\
\hline $104,592,798$ & -1.57 & -1.22 & - & Auxin response factor 8 \\
\hline $104,595,261$ & -2.03 & -1.58 & - & Auxin induced protein AUX22 \\
\hline $104,611,678$ & -2.24 & -2.70 & - & Auxin responsive $\mathrm{GH} 3$ gene family \\
\hline $104,586,117$ & -2.51 & -1.75 & - & Auxin responsive protein IAA28 \\
\hline $104,595,142$ & - & -1.00 & - & Auxin responsive protein IAA27 \\
\hline $109,113,971$ & - & -1.14 & -1.45 & Auxin responsive protein SAUR67 \\
\hline $109,114,265$ & - & -1.16 & -1.50 & Auxin responsive protein SAUR68 \\
\hline $104,587,994$ & - & -1.42 & -1.32 & Auxin responsive protein SAUR23 \\
\hline $104,608,181$ & - & -1.85 & -1.20 & Auxin repressed $12.5 \mathrm{kDa}$ protein \\
\hline $109,114,588$ & - & -1.94 & - & Auxin responsive protein SAUR21 \\
\hline $104,595,095$ & - & -2.36 & - & Auxin induced protein 6B \\
\hline
\end{tabular}

\section{Conclusion}

In this study, we observed that lotus ARs were regulated by light intensity. Therefore, we analyzed genome-wide gene expression by RNA-seq and determined that 1739, 1683, and 1462 genes were upregulated and 1533, 995, and 834 genes were downregulated in the D/CKO, E/CKO, and F/CKO libraries, respectively. We observed that 20 DEGs were involved in signal transduction, and 36 DEGs were related to carbohydrate metabolism. In the F/D libraries, 28 genes relevant to auxin synthesis, transport, response, or binding were found to participate in AR development, and 24 genes related to sucrose metabolism, glucose metabolism, and fructose metabolism changed their expression. According to changes in IAA and sucrose content, we believe that IAA and sucrose cooperatively regulate lotus AR formation.

\section{Methods}

\section{Material preparation}

In this study, Taikong 36, which was bred by the research base of the Guangchang space lotus (this species of lotus, Nelumbo nucifera Gaertn., has been deposited in a publicly available herbarium), was selected for all experimental analyses as there were abundant material resources for this plant. Taikong 36 was harvested from Guangxi province, and grown in the experimental field of the aquatic vegetables research group of Yangzhou University (latitude: 119.42, longitude: 32.39, altitude: $12 \mathrm{~m}$ ), Southeast China with conventional management in spring. In the growing season, the temperature was $30 \pm$ $5^{\circ} \mathrm{C} /$ day and $25 \pm 5^{\circ} \mathrm{C} /$ night, and the average water depth of field (the plant must be maintained in the water) was $30 \pm 10$ $\mathrm{cm}$. The seeds were harvested after $30 \mathrm{~d}$ of flowering and kept in the warehouse under normal temperature conditions. The high activity of lotus seeds can be maintained for 10 years. 
Table 3 Gene expression involved in sucrose, glucose, and fructose metabolism in D/CK, F/CK, and F/D libraries

\begin{tabular}{|c|c|c|c|c|}
\hline ID & D/CKO libraries & E/CKO libraries & F//CKO libraries & Function annotation \\
\hline \multicolumn{5}{|c|}{ Sucrose metabolism } \\
\hline 104606206 & 4.07 & 3.43 & 3.91 & Sucrose synthase 2 \\
\hline 104590896 & 3.38 & 3.37 & - & Sucrose-phosphate synthase 2 \\
\hline 104607575 & 1.64 & 2.34 & 2.18 & Sucrose transport protein SUC4 \\
\hline 104591964 & 1.61 & 1.94 & 1.29 & Galactinol--sucrose galactosyltransferase \\
\hline 104595245 & -1.47 & - & - & VIN3-like protein 1 \\
\hline 104599026 & -1.01 & - & - & Sucrose nonfermenting 4 \\
\hline 104605199 & -1.03 & - & 1.29 & Sucrose-phosphatase 2 \\
\hline 104590476 & -1.93 & -1.47 & -1.37 & Sucrose synthase \\
\hline 104586132 & -2.15 & -2.98 & -1.99 & Galactinol--sucrose galactosyltransferase 6 \\
\hline 104612986 & -2.50 & -2.91 & -2.80 & Galactinol--sucrose galactosyltransferase 2 \\
\hline 104607856 & -3.17 & -2.82 & -3.14 & Sucrose synthas \\
\hline \multicolumn{5}{|c|}{ Glucose metabolism } \\
\hline 104613182 & 3.84 & 3.37 & 2.73 & Facilitated glucose transporter \\
\hline 104611373 & 3.78 & 3.23 & 4.54 & Sugar transport protein 14 \\
\hline 104596455 & 2.64 & - & - & Glucose-1-phosphate adenylyltransferase \\
\hline 104586894 & 2.09 & 1.65 & 1.66 & Sugar transporter ERD6-like 5 \\
\hline 104589792 & 1.83 & 1.83 & 1.57 & Glucosyltransferase \\
\hline 104590530 & 1.52 & - & - & UDP-glycosyltransferase 84B2-like \\
\hline 104606042 & 1.39 & 1.16 & 1.34 & Phosphoglycerate kinase \\
\hline 104598555 & 1.15 & 1.71 & 1.20 & L-lactate dehydrogenase B \\
\hline 104599589 & 1.09 & 1.08 & 1.24 & 6-phosphogluconolactonase 2 \\
\hline 104597981 & -1.00 & - & - & UDP-glucose 6-dehydrogenase 1 \\
\hline 104605632 & -1.09 & - & - & Glucose-induced degradation protein 8 \\
\hline 104601180 & -1.14 & -1.10 & -1.12 & Cytosolic enolase 3 \\
\hline 104605346 & -1.24 & - & - & Hexokinase-2 \\
\hline 104601854 & -1.32 & - & - & Sugar transporter ERD6 \\
\hline 104590451 & -1.52 & -1.26 & -1.36 & UTP-glucose-1-phosphate uridylyltransferase \\
\hline 104591632 & -1.63 & -1.45 & - & Glucose-6-phosphate 1-dehydrogenase \\
\hline 104601106 & -1.72 & -1.62 & -1.19 & UDP-glucose 6-dehydrogenase 4 \\
\hline 104611174 & -1.80 & - & - & Pyruvate kinase \\
\hline 104593418 & -2.86 & -2.54 & -2.83 & Glucose-6-phosphate 1-epimerase \\
\hline 104598792 & -2.96 & - & - & UDP-glucose 6-dehydrogenase 5 \\
\hline 104592969 & -3.63 & -3.04 & -3.67 & Glucose-6-phosphate 1-dehydrogenase \\
\hline \multicolumn{5}{|c|}{ Fructose metabolism } \\
\hline 104602041 & 2.27 & 1.71 & 1.87 & Fructose-bisphosphate aldolase 1 \\
\hline 104595011 & -1.29 & - & - & 6-phosphofructo-2-kinase \\
\hline 104606877 & -1.77 & -1.58 & -1.76 & Pyrophosphate-fructose 6-phosphate 1-phosphotransferase \\
\hline
\end{tabular}

\section{Paraffin section experiments}

The seed coat of Taikong 36 lotus was broken and soaked in water for germination. The seedlings of lotus were exposed to various light intensities including darkness, and 5000, and 20,000 $\mathrm{lx}$ at a temperature of $30^{\circ} \mathrm{C} /$ day and $20^{\circ} \mathrm{C} /$ night. Lotus hypocotyls were chosen at day $0,1,2,3,4$, and 5 post-treatment. Hypocotyls sections of $2 \mathrm{~mm} \times 2 \mathrm{~mm} \times 2 \mathrm{~mm}$ (length $\times$ width $\times$ height) were prepared and placed into a small container with approximately $10 \mathrm{~mL}$ free fatty acid fixing fluid (at a 20:1 volume of free fatty acid fixing fluid to each sample). A vacuum condition in a the small container was made 
with a syringe, and the samples of these treatments were transferred to this vacuum environment for $10 \mathrm{~s}$, and then gas was exchanged for $10 \mathrm{~min}$. The above process was repeated three times at $25^{\circ} \mathrm{C}$ overnight. Then, various concentrations of ethanol $(50,60,70,80,90$, and $100 \%)$ were prepared and used to treat samples for 20 min sequentially. These dehydrated samples were put into a mixed solution (pure xylene: absolute ethanol; 1 : 1 ), and then transferred to pure xylene for approximately 20-30 min. The samples wrapped in paraffin were placed in a container for at least $12 \mathrm{~h}$ at normal temperature, and then transferred into thawed paraffin wax for $18-24 \mathrm{~h}$ for preparing paraffin blocks. An incisive slicer was used to prepare a $10 \mu \mathrm{m}$ thick wax tape, which was then placed on the glass slide. The samples on the glass slide were treated in turn with xylene, mixed solution (pure xylene: absolute ethanol; 1:1), and absolute ethanol for approximately $10 \mathrm{~min}$. Finally, these slides were dried in air under normal temperature conditions, and the tissues on the slide were identified using an optical microscope.

\section{RNA-sequencing analysis}

For this experiment, the lotus seed coat was broken for available uptake of water, germinated at $28-30{ }^{\circ} \mathrm{C}$, and then transferred into a container with $5 \mathrm{~cm}$ of water depth for growth. The one-leaf seedlings were placed into three light intensities, including darkness, $5000 \mathrm{~lx}$, and 20,000 lx for AR analysis. The materials of these treatments were chosen at day 0 (CKO), and day 3 (library D was constructed from samples under darkness; library E was constructed from samples from $5000 \mathrm{~lx}$ treatment; and library F was constructed from samples from 20,000 lx treatment). The total RNA of hypocotyls was prepared and digested with DNase I for purification. Approximately $3 \mu \mathrm{g}$ of RNA from each sample was used for library construction. Sample preparation kits for Illumina gene expression were used for CK0, D, E, and F library construction. Processing of libraries were completed as previously described [32]. The detailed work was completed by the Beijing Institute of Genomics (BIG) with a special construct.

\section{Screening of differentially expressed genes}

DEGs of differential libraries were screened as previously described method [71, 72]. Further analysis of reads derived from all libraries was carried out by the NOISeq technique [32]. The $\log 2$ (fold-change) $M$ was used as the relative expression of genes in each library, and the noise distribution model was built according to the absolute value of difference $(\mathrm{N})$. To identify whether gene A was differentially expressed, the average expression in control group (control_avg) and treatment group (treat_ avg) was first computed, and then the values of different expressing change and "N" were obtained according to the data of fold change $(\mathrm{MA}=\log 2$ ((treat_avg)/(control_ avg)) ) and the absolute value of difference (NA = $\mid$ control_avg - treat_avg|). Finally, gene A was considered as a DEG if MA and NA measured by probability value diverged significantly from the noise distribution model. Totally, if the fold change of expressed gene A was greater than two and the divergence probability was greater than 0.8 then gene A was accepted as a DEG.

\section{Functional analysis of the DEGs}

The DEGs in each library involved in molecular function, cellular component, and biological process were annotated using the Gene Ontology (GO) tool. The biological function of DEGs was obtained by comparing results with the National Center for Biotechnology Information (NCBI) database. The number of DEGs involved in the above three ontologies was computed after comparison with the GO database (http://www.geneontology.org/), and then the DEGs were collected together as GO terms by hypergeometric test. In addition, the KEGG tool was used to identify which metabolic processes these DEGs were enriched in.

\section{Relative expression analysis}

The relative expression of several important genes was documented to identify the changes in metabolism under various light intensity treatments. The lotus seed treatment and cultivation conditions were the same as mentioned above. The samples were collected at 0 (germinated seeds) and day 3 (germinated seeds that were cultivated for 3 days in darkness, and under 5000 and 20,000 lx conditions). qRT-PCR was applied to monitor changes in gene expression, as previously described [11; 69]. The RNA extraction mini kit (QIAGEN, Germany) was used to obtain the total RNA of lotus hypocotyls, and DNA contamination was removed by DNaseI. First Strand cDNA Synthesis Kit (Fermentas, USA) [73] was used to synthesize cDNA (approximately 3-5 $\mu$ g of total RNA). The transcriptional level was investigated using SYBR Green Master Mix (Tiangen, China) on an Mx 3000P machine (STRATAGENE, http:// www.stratagene. com) [61] with three repeated experiments. The primers of selected genes were derived from the NCBI database, and $\beta$-Actin was used as the reference gene to measure gene expression. The primers for $\beta$-Actin were: upstream, $5^{\prime}$ AACCTCCTCCTCATCGTACT-3', and downstream, 5' GACAGCATCAGCCATGTTCA-3'; the primers of the chosen genes are listed in Additional file 1: Table S2. The total volume of the PCR reaction system was $25 \mu \mathrm{L}$ including $12.5 \mu \mathrm{L}$ Premix Ex Taq II (TliRNaseH Plus) $(2 \times)$ SYBR (Tiangen, China), $10 \mu \mathrm{M}$ each of forward and reverse primers, $2 \mu \mathrm{L}$ cDNA solution, and $8.5 \mu \mathrm{L}$ distilled water. The PCR program was run at $94{ }^{\circ} \mathrm{C}$ for $30 \mathrm{~s}$, followed by 40 
cycles of $95^{\circ} \mathrm{C}$ for $5 \mathrm{~s}$ and $55^{\circ} \mathrm{C}-60^{\circ} \mathrm{C}$ for $60 \mathrm{~s}$. The data analysis was performed using the $2^{-\Delta \Delta \mathrm{Ct}}$ method [48].

\section{Analysis of IAA content}

The seeds of lotus were broken and then put into a container with $5 \mathrm{~cm}$ water in depth for germination at $26^{\circ} \mathrm{C}$ for approximately $4-5 \mathrm{~d}$. The germinated seeds were transferred into four light intensities for continuous growth (under darkness, and under 5000, 15,000, and $30,000 \mathrm{~lx}$ ); hypocotyls of lotus seedlings were selected at $0,2,4,6,8$, and $10 \mathrm{~d}$ of each treatment for IAA identification according to the following procedure. First, the hypocotyls of each treatment were put into liquid nitrogen to grind into powder, and then $50 \mathrm{mg}$ of sample powder was transferred into a $2 \mathrm{~mL}$ centrifuge tube, which was pre-cooled in advance. Next, approximately $500 \mu \mathrm{L}$ of extraction reagent $(\mathrm{V} / \mathrm{V} / \mathrm{V}$ : isopropyl alcohol: water: concentrated hydrochloric acid $=2: 1: 0.002$ ) was added to the tuber. The tubers were oscillated at $4{ }^{\circ} \mathrm{C}$ for $30 \mathrm{~min}$ at $100 \mathrm{rpm}$, and $1 \mathrm{~mL}$ dichloromethane was added. After shaking at $4{ }^{\circ} \mathrm{C}$ for $30 \mathrm{~min}$, the mixed solution was centrifuged at $12,000-13,000 \mathrm{rpm}$ at $4{ }^{\circ} \mathrm{C}$ for 5 min. The lower layer of the supernatant $(900 \mathrm{~mL})$ was extracted and dried with nitrogen; $100 \mathrm{~mL}$ of filtered methanol was added to dissolve the dry powder. The sample $(50 \mathrm{~mL})$ was injected into the $\mathrm{C} 18$ column of liquid chromatography (Sigma, Germany) for IAA identification.

\section{Complementary effect of sucrose on IAA treatment of lotus ARs}

Lotus seed was broken for available uptake water, and then was divided into four groups. The seeds of the first group were placed in water for germination, and the second group was treated with $150 \mu \mathrm{M}$ IAA for 2 days and then transferred to water for germination. The seeds of the third group were put into $20 \mathrm{~g} / \mathrm{L}$ sucrose for 2 days and then transferred into water, and the seeds of the fourth group were placed into the solution with $20 \mathrm{~g} / \mathrm{L}$ and $150 \mu \mathrm{M}$ IAA for 2 days. The conditions of germination, including temperature, water depth, and light intensity, were the same as described above. After germination of seeds, the number of ARs was counted with an interval of 1 day within 6 days. The experiment was repeated three times.

\section{Supplementary information}

Supplementary information accompanies this paper at https://doi.org/10. 1186/s12864-020-07098-5.

Additional file 1: Fig S1. Analysis of sequencing data saturation in CK, D, and $E$ and $F$ libraries. a. CO library. b. D library. C. E library. d. F library. Differentially expressed genes in D/CK, E/CK, F/CK, and F/D. libraries. Table S1. Information on tags obtained by RNA-seq technology in all the libraries. Table S2.The primers of genes used for mRNA level analysis qRT-PCR method.

\section{Abbreviations}

ARs: Adventitious roots; IAA: Indole-3-acetic acid; DEGs: Differentially expressed genes; PCR: Polymerase chain reaction; qRT-PCR: Reversetranscriptase quantitative PCR

\section{Acknowledgements}

We extend our thanks to members of the BIG for their cooperation in obtaining the data during the AR formation of the lotus by RNA-seq technique. The authors also thank Editage for their editorial assistance.

\section{Authors' contributions}

The manuscript has been revised and approved by all the authors. $\mathrm{CL}, \mathrm{HZ}$, and LS designed the experiment; WC, HY and SZ performed the research; WC, ZM and HY analyzed the data. XX and CL participated in the sequence analysis. $\mathrm{CL}$ and $\mathrm{LS}$ wrote the paper, and $\mathrm{HZ}$ modified the manuscript.

\section{Funding}

This work was supported by Jiangsu Agriculture Science, Technology Innovation Fund (CX (18) 3066), the modern agriculture of Yangzhou (YZ2017044), and a special project of north Jiangsu (SZ-YC2019008). The cost of experimental work was supported by CX (18) 3066 and YZ2017044, and the publication cost was supported by SZ-YC2019008. All the funder lists in this manuscript have no role in the design and performance of all the experiments, analysis of data, and in the writing of the text file.

\section{Availability of data and materials}

The materials of all the experiments were supported by the aquatic vegetable Laboratory of Yangzhou University. Detailed data has been deposited in the NCBI database (Biosample number, CKO_1 CKO_3: SAMN13000907 SAMN13000909, CKO_1-CKO_3: SAMN13000910

SAMN13000912; E_1 E_3: SAMN13000913 SAMN13000915; E_1 E_3: SAMN13000916 SAMN13000918; Bioproject number: 576670).

Ethics approval and consent to participate

Not applicable.

\section{Consent for publication}

Not applicable.

\section{Competing interests}

The authors declare that they have no competing interests.

\section{Author details}

${ }^{1}$ School of Horticulture and Plant Protection, Yangzhou University, Yangzhou, Jiangsu, P. R. China. ${ }^{2}$ Key Laboratory of Plant Stress Biology, School of Life Sciences, Henan University, Kaifeng 475004, China. ${ }^{3}$ Henghui Food Co., Ltd of Yancheng, Kaifeng 224700, China. ${ }^{4}$ College of Guangling, Yangzhou University, Yangzhou, Jiangsu, P. R. China.

Received: 6 March 2020 Accepted: 23 September 2020

Published online: 12 October 2020

\section{References}

1. Cheng LB, Ying JJ, Yang JQ, Li Y, Hui LC, Li SY, et al. Activity and expression of ADP-glucose pyrophosphorylase during rhizome formation in lotus (Nelumbo nucifera Gaertn.). Bot Stud. 2016;9:57.

2. Shen-Miller J. Sacred lotus, the long-living fruits of China antique. Seed Sci Res. 2002:12:131-43.

3. Ming R, VanBuren R, Liu YL, Yang M, Han YP, Li LT, et al. Genome of the Long living sacred lotus (Nelumbo nucifera Gaertn.). Genome Biol. 2013;14:R41.

4. Yadav SKS, Patral D, Singh S, Sarkar A, Panigrahil KCS. Uncovering the molecular signature underlying the light intensity-dependent root development in Arabidopsis thaliana. BMC Genomics. 2019:20:596.

5. Kelly JWG, Landhäusser SM, Chow PS. The impact of light quality and quantity on root-to-shoot ratio and root carbon reserves in aspen seedling stock. New For. 2015;46(4):527-45. 
6. Wang F, Zhang L, Chen X, Wu X, Xiang X, Zhou J, Xia X, Shi K, Yu J, Foyer $\mathrm{CH}$, Zhou YH. SIHY5 integrates temperature, light and hormone signaling to balance plant growth and cold tolerance. Plant Physiol. 2019;179:749-60.

7. de Wit M, Galvão VC, Fankhauser C. Light-mediated hormonal regulation of plant growth and development. Annu Rev Plant Biol. 2016;67:513-53.

8. Li B, Fan R, Guo S, Wang P, Zhu X, Fan Y, Chen Y, He K, Kumar A, Shi J, Wang Y, Li L, Hu Z, Song C-P. The Arabidopsis MYB transcription factor MYB111 modulates salt responses by regulating flavonoid biosynthesis. Environ Exp Bot. 2019a;166:103807.

9. Alabaid D, Blazquez M. Molecular interactions between light and hormone signaling to control plant growth. Plant Mol Biol. 2009;69:409-17.

10. Qu X, Cao B, Kang J, Wang X, Han X, Jiang W, Shi X, Zhang L, Cui L, Hu Z, Zhang $Y$, Wang G. Fine-tuning stomatal movement through small signaling peptides. Front Plant Sci. 2019;10:69.

11. Li C, Zheng L, Wang X, Hu Z, Zheng Y, Chen Q, Hao X, Xiao X, Wang X, Wang G, Zhang Y. Comprehensive expression analysis of Arabidopsis GA2oxidase genes and their functional insights. Plant Sci. 2019b;285:1-13.

12. Burbach C, Markus K, Zhang Y, Schlicht M, Baluška F. Photophobic behavior of maize roots. Plant Signal Behav. 2012;7(7):874-8.

13. Canamero RC, Bakrim N, Bouly JP, Garay A, Dudkin EE, Habricot Y. Cryptochrome photoreceptors cry 1 and cry2 antagonistically regulate primary rooelongation in Arabidopsis thaliana. Planta. 2006;224(5):995-1003.

14. Kumari S, Yadav S, Patra D, Singh S, Sarkar AK, Panigrahi KCS. Uncovering the molecular signature underlying the light intensity-dependent root development in Arabidopsis thaliana. BMC Genomics. 2019;20:596.

15. Ha JH, Kim JH, Kim SG, Sim HJ, Lee G, Halitschke R. Shoot phytochrome B modulates reactive oxygen species homeostasis in roots via abscisic acid signaling in Arabidopsis. Plant J. 2018;94(5):790-8.

16. Meng L, Song W, Liu S, Dong J, Zhang Y, Wang C. Light quality regulates lateral root development in tobacco seedlings by shifting Auxin distributions. J Plant Growth Regul. 2015;34(3):574-83.

17. Nagel KA, Schurr U, Walter A. Dynamics of root growth stimulation in Nicotiana tabacum in increasing light intensity. Plant Cell Environ. 2006;29(10):1936-45.

18. Ken YW, Tomokazu KB, Frantisek B. Light-dependent control of redox balance and auxin biosynthesis in plant. Plant Signal Behav. 2014;9(6): e29522. https://doi.org/10.4161/psb.29522.

19. Koshiba T, Yamanchi K, Matsuyama H, Miyakado M, Sori I. Flavinphotosensitized production of indole-3-acetaldehyde from tryptophan. Tetrahedrom Lett. 1993;34:7603-6.

20. Della Rovere F, Fattorini L, D'Angeli S, Veloccia A, Falasca G, Altamura MM. Auxin and cytokinin control formation of the quiescent Centre in the adventitious root apex of Arabidopsis. Ann Bot. 2013;112:1395-407.

21. Fukaki H, Tasaka M. Hormone interactions during lateral root formation. Plant Mol Biol. 2009;69:437-49.

22. Nag S, Saha K, Choudhuri MA. Role of auxin and polyamines in adventitious root formation in relation to changes in compounds involved in rooting. J Plant Growth Regul. 2001;20:182-94.

23. Negi S, Sukumar P, Liu X, Cohen JD, Muday GK. Genetic dissection of the role of ethylene in regulating auxin-dependent lateral and adventitious root formation in tomato. Plant J. 2010;61:3-15.

24. Visser E, Cohen JD, Barendse G, Blom C, Voesenek L. An ethylene-mediated increase in sensitivity to auxininduces adventitious root formation in flooded rumex palustris Sm. Plant Physiol. 1996;112:1687-92.

25. Liu HJ, Wang SF, Yu XB, Yu J, He XW, Zhang SL, et al. ARL1, a LOB-domain protein required for adventitious root formation in rice. Plant J. 2005;43:47-56.

26. Marchant A, Bhalerao R, Casimiro I, Eklöf J, Casero PJ, Bennett M, et al. AUX1 promotes lateral root formation by facilitating indole-3-acetic acid distribution between sink and source tissues in the Arabidopsis seedling Plant Cell. 2002;14:589-97.

27. Carraro N, Tisdale-Orr TE, Clouse RM, Knoller AS, Spicer R. Diversification and expression of the PIN, AUX/LAX, and ABCB families of putative auxin transporters in Populus. Front Plant Sci. 2012;3:17.

28. Ahkami AH, Melzer M, Ghaffari MR, Pollmann S, Javid MG, Shahinnia F, Hajirzzae MR, Druege U. Distribution of indole-3-acetic acid in petunia hybridashoot tip cuttings and relationship between auxin transport, carbohydrate metabolism and adventitious root formation. Planta. 2013;238:499-517.

29. Sauer M, Balla J, Luschnig C, Wisniewska J, Reinöhl V, Friml J, et al. Canalization of auxin flow by aux/IAA-ARF-dependent feedback regulation of PIN polarity. Genes Dev. 2006;20:2902-11.
30. Xu M, Zhu L, Shou HX, Wu P. A PIN1 family gene, OsPIN1, involved in auxindependent adventitious root emergence and tillering in Rice. Plant Cell Physiol. 2005:46:1674-81.

31. Gutierrez L, Bussell JD, Păcurar DI, Schwambach J, Păcurar M, Bellini C. Phenotypic plasticity of adventitious rooting in Arabidopsis is controlled by complex regulation of auxin response factor transcripts and MicroRNA abundance. Plant Cell. 2009;21:3119-32.

32. Cheng LB, Jiang RZ, Yang JJ, Xu XY, Zeng HT, Li SY. Transcriptome profiling reveals an IAA-regulated response to adventitious roots formation in lotus seedling. Zeitschrift fur Nat. 2018;73(5-6):229-40.

33. Cheng LB, Liu HY, Jiang RZ, Li SY. A proteomics analysis of adventitious root formation after leaf removal in lotus (Nelumbo nucifera Gaertn.). ZNC. 2018b;73:375-89.

34. Falasca G, Zaghi D, Possenti M, Altamura MM. Adventitious root formation in Arabidopsis thaliana thin cell layers. Plant Cell Rep. 2004;23:17-25.

35. Li SW, Leng $Y$, Feng $L$, Zeng $X Y$. Involvement of abscisic acid in regulatin antioxidativedefensesystems and IAA-oxidase activity and improving adventitious rooting in mung bean [Vignaradiata (L.)Wilczek] seedlings under cadmium stress. Environ Sci Pollut Res. 2014;21:525-37.

36. Kevers C, Hausman JF, Faivre-Rampant O, Evers D, Gaspar T. Hormonal control of adventitious rooting: progress and questions. J Appl Bot Angew Bot. 1997;71:71-9.

37. Li SW, Xue L, Xu S, Feng H, An L. Mediators, genes and signaling in adventitious rooting. Bot Rev. 2009;75:230-47.

38. Rasmussen A, Hosseini SA, Hajirezaei MR, Druege U, Geelen D. Adventitious rooting declines with the vegetative to reproductive switch and involves a changed auxin homeostasis. J Exp Bot. 2015;66:1437-52.

39. Teale WD, Paponov IA, Palme K. Auxin in action: signaling, transport and the control of plant growth and development. Nat Rev Mol Cell Biol. 2006;7:847-59.

40. Najafabadi AS, Khanahmadi M, Ebrahimi M, Moradi K, Behroozi P, Noormohammadi N. Effect of different quality of light on growth and production of secondary metabolites in adventitious root cultivation of Hypericum perforatum. Plant Signal Behav. 2019. https://doi.org/10.1080/ 15592324.2019;1640561.

41. Chen YM, Huang JZ, Hou TW, Pan C. Efects of light intensity and plant growth regulators on callus proliferation and shoot regeneration in the ornamental succulent Haworthia. Bot Stud. 2019;60:10.

42. Cho KH, Laux VY, Wallace-Springer N, Clark DG, Folta KM, Colquhoun TA. Effects of light quality on vegetative cutting and in vitro propagation of coleus (Plectranthus scutellarioides). Hort. 2019;54:926-35.

43. Druege U, Hilo A, Pérez-Pérez JM, Klopotek Y, Acosta M, Shahinnia F, Zerche S, Franken P, Hajirezaei MR. Molecular and physiological control of adventitious rooting in cuttings: phytohormone action meets resource allocation. Ann Bot. 2019:123:929-49.

44. Rapaka VK, Bessler B, Schreiner M, Druege U. Interplay between initial carbohydrate availability, current photosynthesis and adventitious root formation in Pelargonium cuttings. Plant Sci. 2005;168:1547-60.

45. Zerche S, Druege U. Nitrogen content determines adventitious rooting in Euphorbia pulcherrima under adequate light independently of pre-rooting carbohydrate depletion of cuttings. Sci Hortic. 2009;121:340-7.

46. Calvo-Polanco M, Senorans J, Zwiazek JJ. Role of adventitious roots in water relations of tamarack (Larix laricina) seedlings exposed to flood. BMC Plant Biol. 2012;12:99.

47. Cheng LB, Han YY, Liu HY, Jiang RZ, Li SY. Transcriptomic analysis reveals ethylene's regulation involved in adventitious roots formation in lotus (Nelumbo nucifera Gaertn.). Acta Physiol Plant. 2019;41:97.

48. Cheng LB, Liu HY, Han YY, Li SY. Transcriptome analysis of miRNAs expression reveals novel insights into adventitious root formation in lotus (Nelumbo nucifera Gaertn.). Mol Biol Rep. 2019;46:2893-905.

49. Xiao TW, Mi MM, Wang CY, Qian M, Chen YH, Zheng LQ, Zhang HS, Hu ZB, Shen ZG, Xia Y. A methionine-R-sulfoxide reductase, OsMSRB5, is required for rice defense against copper toxicity. Environ Exp Bot. 2018;153:45-53.

50. Cui F, Wu W, Wang K, Zhang Y, Hu Z, Brosché M, Liu S, Overmyer K. Cell death regulation but not abscisic acid signaling is required for enhanced immunity to Botrytis in Arabidopsis cuticle-permeable mutants. J Exp Bot. 2019;70:5971-84.

51. Ke YG, Abbas F, Zhou YW, Yu RC, Yue YC, Li XY, Yu YY, Fan YP. Genomewide analysis and characterization of the aux/iaa family genes related to floral scent formation in Hedychium coronarium. Int J Mol Sci. 2019;20:3235. 
52. Vanneste S, Friml J. Auxin: a trigger for change in plant development. Cell. 2009:136:1005-16.

53. Christopher J, Christopher M, Jennings R, Jones S, Fletcher S, Borrell A, et al. QTL for root angle and number in a population developed from bread wheats (Triticumaestivum) with contrasting adaptation to water-limited environments. Theor Appl Genet. 2013;126:1563-74.

54. Rovere FD, Fattorini L, Angeli SD, Veloccia A, Duca SD, Cai G, et al. Arabidopsis SHR and SCR transcription factors and AUX1 auxin influx carrier control the switch between adventitious rooting and xylogenesis in planta and in in vitro cultured thin cell layers. Ann Bot. 2015;115:617-28.

55. Friml J, Vieten A, Sauer M, Weijers D, Schwarz H, Hamann T, et al. Effluxdependent auxin gradients establish the apical-basal axis of Arabidopsis. Nature. 2003;426:147-53.

56. Ljung K, Hull AK, Celenza J, Yamada M, Estelle M, Normanly J, et al. Sites and regulation of auxin biosynthesis in Arabidopsis roots. Plant Cell. 2005; 17:1090-104.

57. Casimiro I, Marchant A, Bhalerao RP, Beeckman T, Dhooge S, Swarup R. Auxin transport promotes Arabidopsis lateral root nitiation. Plant Cell. 2001; 13:843-52.

58. Hobbie L, Estelle M. The axr4 auxin-resistant mutants of Arabidopsis thaliana define a gene important for root gravitropism and lateral root initiation. Plant J. 1995:7:211-20.

59. Rolland F, Baena-Gonzalez E, Sheen J. Sugar sensing and signaling in plants: conserved and novel mechanisms. Annu Rev Plant Biol. 2006;57:675-709.

60. Lastdrager J, Hanson J, Smeekens S. Sugar signals and the control of plant growth and development. J Exp Bot. 2014;65:799-807.

61. Riou-Khamlichi C, Menges M, Healy JM, Murray JA. Sugar control of the plant cell cycle: differential regulation of Arabidopsis D-type cyclin gene expression. Mol Cell Biol. 2000;20:4513-21.

62. Komaki S, Sugimoto K. Control of the plant cell cycle by developmental and environmental cues. Plant Cell Physiol. 2012;53:953-64.

63. Cano-Delgado Al, Metzlaff K, Bevan MW. The eli1 mutation reveals a link between cell expansion and secondary cell wall formation in Arabidopsis thaliana. Development. 2000;127:3395-405.

64. Le KC, Kim HH, Park SY. Modification of the droplet-vitrification method of cryopreservation to enhance survival rates of adventitious roots of Panax ginseng. Hortic Environ Biotechnol. 2019;60:501-10.

65. Gao Y, Wu CH, Piao XC, Han L, Gao R, Lian ML. Optimization of culture medium components and culture period for production of adventitious roots of Echinacea pallida (Nutt.). Plant Cell Tiss Org. 2018;135:299-307.

66. Takahashi F, Sato-Nara K, Kobayashi K, Suzuki M, Suzuki H. Sugar-induced adventitious roots in Arabidopsis seedlings. J Plant Res. 2003;116:83-91.

67. Kaur H, Kaur K, Gill GK. Modulation of sucrose and starch metabolism by salicylic acid induces thermotolerance in spring maize. Russ J Plant Physiol. 2019;66:771-7.

68. Zhang JH, Li CY, Wei ML, Ge YH, Tang Q, Xue WJ, Zhang SY, Wang WH, Lv JY. Effects of trisodium phosphate treatment after harvest on storage quality and sucrose metabolism in jujube fruit. 2019. J Sci Food Agric. 2019;99:5526-32.

69. Chen YR, Ge YH, Zhao JR, Wei ML, Li CY, Hou JB, Cheng Y, Chen JX. Postharvest sodium nitroprusside treatment maintains storage quality of apple fruit by regulating sucrose metabolism. Postharvest Biol Technol. 2019;154:115-20.

70. Stepanova AN, Yun J, Likhacheva AV, Alonso JM. Multilevel interactions between ethylene and auxin in Arabidopsis roots. Plant Cell. 2007;19:2169-85.

71. Bhosale R, Boudolf V, Cuevas F, Lu R, Eekhout T, Hu ZB, et al. A spatiotemporal dna endoploidy map of the arabidopsis root reveals roles for the endocycle in root development and stress adaptation. Plant Cell. 2018;30:2330-51.

72. Li L, Hou MJ, Cao L, Xia Y, Shen ZG, Hu ZB. Glutathione S-transferases modulate Cu tolerance in Oryza sativa. Environ Exp Bot. 2018;155:313-20.

73. Jiao K, Li X, Guo Y, Guan Y, Guo W, Luo D, Hu, and Shen Z. Regulation of compound leaf development in mungbean (Vigna radiata L.) by cup-shaped copyledon/no apicalmeristem (cuc/nam) gene. Planta. 2019;249:765-74.

\section{Publisher's Note}

Springer Nature remains neutral with regard to jurisdictional claims in published maps and institutional affiliations.

\section{Ready to submit your research? Choose BMC and benefit from}

- fast, convenient online submission

- thorough peer review by experienced researchers in your field

- rapid publication on acceptance

- support for research data, including large and complex data types

- gold Open Access which fosters wider collaboration and increased citations

- maximum visibility for your research: over $100 \mathrm{M}$ website views per year

At BMC, research is always in progress.

Learn more biomedcentral.com/submissions 